\title{
Irrigação com água salina em solo com biofertilizante bovino no crescimento do maracujazeiro amarelo
}

\section{Irrigation with saline water in soil with bovine biofertilizer on the growth in the yellow passion fruit}

\author{
Thiago Jardelino Dias ${ }^{1 *}$; Lourival Ferreira Cavalcante ${ }^{2}$; Walter Esfrain Pereira ${ }^{3}$; \\ José Lucínio de Oliveira Freire ${ }^{4}$; Antônio Gustavo de Luna Souto ${ }^{5}$
}

\begin{abstract}
Resumo
As plantas respondem diferenciadamente aos efeitos dos sais nas distintas fases do seu ciclo; algumas crescem adequadamente e produzem com viabilidade econômica em solos com salinidade elevada, outras, como o maracujazeiro amarelo, têm o desenvolvimento comprometido pela ação salina do solo e da água de irrigação. O objetivo do trabalho foi avaliar os efeitos de níveis crescentes de salinidade da água de irrigação em solo tratado com diferentes frequências de aplicação de biofertilizante bovino sobre o crescimento vegetativo do maracujazeiro amarelo. $\mathrm{O}$ experimento foi instalado em blocos casualizados, com os tratamentos distribuídos em arranjo fatorial $5 \times 4$, correspondente aos valores de condutividade elétrica da água de irrigação: 0,$5 ; 1,5 ; 2,5 ; 3,5$ e $4,5 \mathrm{dS} \mathrm{m}^{-1}$ e quatro frequências de aplicação do insumo: sem biofertilizante (SB); uma semana antes do transplantio (1SAT); a cada 90 dias a partir do transplantio (90DAT); e, uma semana antes e a cada 90 dias apos o transplantio (1SAT+90DAT). O efeito da condutividade elétrica da água de irrigação reduziu o crescimento das plantas de maracujazeiro, atrasando o período de floração da cultura. O biofertilizante aplicado 1SAT e 1SAT+90DAT estimulou o crescimento das plantas de maracujazeiro amarelo atenuando os efeitos salinos da água de irrigação.

Palavras-chave: Passiflora edulis, condutividade elétrica, efluente orgânico, irrigação, crescimento
\end{abstract}

\begin{abstract}
The plants respond differently to the effects of salts in the distinct phases of their cycle, some grow and produce properly with economic viability in soils with high salinity, others, such as passion fruit development are compromised by the action of saline soil and irrigation water. The objective of this study was to evaluate the effects of increasing levels of salinity of irrigation water in soil treated with different frequencies of application of bovine biofertilizers on vegetative growth veal yellow passion fruit. The experiment was randomized block with treatments distributed in a $5 \times 4$ factorial design corresponding to levels of electrical conductivity of the irrigation water of $0.5 ; 1.5 ; 2.5 ; 3.5$ and $4.5 \mathrm{dS} \mathrm{m}^{-1}$ and four frequencies of the application of bovine biofertilizer: absence of biofertilizer (SB); application of bovine biofertilizer one week before transplanting (1SAT); application every 90 days after transplanting
\end{abstract}

1 Prof. do Dept ${ }^{\circ}$ de Agropecuária, Centro de Ciências Humanas, Sociais e Agrárias da Universidade Federal da Paraíba, CCHSA/ UFPB, Bananeiras, PB. E-mail: thiago@cchsa.ufpb.br

2 Visiting Prof. Sênior, Centro de Ciências e Tecnologia Agroalimentar, Universidade Federal de Campina Grande, CCTA/UFCG, Pombal, PB. E-mail: lofeca@cca.ufpb.br

3 Prof. do Dept ${ }^{\circ}$ de Ciências Fundamentais e Sociais, CCA/UFPB, Areia, PB. E-mail: wep@cca.ufpb.br

4 Prof. do Instituto Federal da Paraíba, Campus de Picuí, Picuí, PB. E-mail: luciniooliveira@yahoo.com.br

5 Discente de Mestrado em Agronomia, Programa de Pós-graduação em Agronomia, Universidade Federal da Paraíba, PPGA/ UFPB, Areia, PB. E-mail: gusluso@hotmail.com

Autor para correspondência 
(90DAT); and, applied one week before and every 90 days after transplanting (1SAT+90DAT). The electrical conductivity of irrigation water reducing the growth of passion fruit, delaying the timing of flowering of culture. The biofertilizer 1SAT and 1SAT+90DAT, the largest number of applications stimulated the growth of yellow passion fruit plants mitigating the effects of saline irrigation water.

Key words: Passiflora edulis, electrical conductivity, organic effluent, irrigation, growth

\section{Introdução}

A atividade agrícola, referente à produção e comercialização de frutas, se encontra em expansão, graças à consolidação dos polos agrícolas e o uso de tecnologias que propiciaram melhorias do sistema produtivo. Esses requisitos, dentre muitos outros, contribuíram para que o agronegócio constitua uma das principais receitas da economia brasileira (CAVICHIOLI et al., 2011; ARAÚJO et al., 2012).

Apesar da expansão de áreas agrícolas, o aumento da produção nem sempre resulta em incremento da produtividade e da qualidade do produto obtido. Essa controvérsia evidencia a necessidade de planejamento e da adoção de tecnologias de produção, principalmente nas regiões áridas e semiáridas, caracterizadas pela combinação de intensa evaporação, irregularidade de precipitação pluviométrica e deficiência em drenagem dos solos, que são fatores limitantes à exploração agrícola, além de contribuírem para a ocorrência de acúmulo de sais no solo e na água, em quantidades prejudiciais ao crescimento normal das plantas (NEVES et al., 2009; DIAS et al., 2011a).

A presença de sais em concentrações elevadas no solo pode alterar as funções fisiológicas e bioquímicas nas plantas, resultando em efeitos negativos na germinação e no crescimento inicial durante a produção das mudas, inibindo o crescimento e o estabelecimento da cultura no campo, principalmente em culturas de elevada sensibilidade à ação dos sais, como o maracujazeiro amarelo (AYERS; WESTCOT, 1999; MUNNS; TESTER, 2008).

Diante dessa situação, fazem-se necessárias adoções de técnicas que reduzam os efeitos negativos da salinidade durante o crescimento inicial do maracujazeiro amarelo, de modo a diminuir a heterogeneidade no crescimento, perdas de rendimento e da qualidade da produção (CAVALCANTE et al., 2009a; BEZERRA et al., 2010).

O biofertilizante bovino é um comporto orgânico bastante utilizado pelos agricultores rurais como uma alternativa viável e econômica, sendo recomendado tanto na adubação, como também no controle de fitomoléstias, reduzindo assim os custos com insumos e defensivos (MESQUITA et al., 2007; SOUZA et al., 2012).

O biofertilizante bovino quando aplicado via solo na forma líquida proporciona melhorias na velocidade de infiltração da água, devido presença de compostos bioativos e substancias húmicas oriundos da fermentação da matéria orgânica (SOUZA et al. 2008; ALVES et al., 2009), que podem contribuir para otimizar as condições edáficas, principalmente sobre as propriedades físicas (TEJADA et al., 2008; DIAS et al., 2011b). Nesse sentido o biofertilizante pode ser uma alternativa para atenuar parcialmente os efeitos da salinidade do solo, possibilitando o uso de águas salinas durante a formação de mudas e crescimento das plantas (CAVALCANTE et al., 2010; OULD AHMED; MORITANI, 2010).

O trabalho deve como objetivo avaliar os efeitos de níveis crescentes da condutividade elétrica da água de irrigação e diferentes frequências de aplicação do biofertilizante líquido bovino aplicado no solo sobre o crescimento vegetativo do maracujazeiro amarelo. 


\section{Material e Métodos}

O experimento foi conduzido no município de Remígio, PB (6 $\left.6^{0} 53^{\prime} \mathrm{S} ; 36^{\circ} 02^{\prime} \mathrm{W}\right)$ no período de setembro de 2008 a agosto de 2010 , em pomar de maracujazeiro amarelo. Segundo a classificação de Köppen adaptado ao Brasil (COELHO; SONCIN, 1982), o clima do município é do tipo As', quente e úmido, registrando no período experimental, temperatura média do ar de $24,8{ }^{\circ} \mathrm{C}$, umidade média do ar de $74,8 \%$ e precipitação acumulada de 1.505 $\mathrm{mm}$.

O delineamento experimental foi em blocos casualizados, seguindo o arranho fatorial $5 \times 4$, referente aos níveis de condutividade elétrica da água de irrigação - CEai $(0,5 ; 1,5 ; 2,5 ; 3,5$ e 4,5 dS $\mathrm{m}^{-1}$ ) e as frequências de aplicação de biofertilizante bovino: SB - sem a aplicação do biofertilizante; 1SAT - aplicação uma semana antes do transplantio; 90DAT - aplicação a cada 90 dias a após o transplantio; e, 1SAT+90DAT - aplicação uma semana antes e a cada 90 dias após o transplantio.

As mudas foram obtidas a partir de sementes extraídas de acesso de genótipo recolhido na região produtora de Nova Floresta (PB), oriundas de maracujás frescos, lavadas, retiradas a mucilagem e postas para secar a sombra durante três dias. Em seguida foram tratadas com o fungicida (Thiophanate methyl) e alocadas em recipientes de polietileno preto, bem drenado com dimensões de 18 x $10 \mathrm{~cm}$ de altura e largura, respectivamente, contendo substratos constituído por solo retirado da camada de 0-20 cm da área experimental submetido à solarização, mantendo por uma semana coberto com plástico transparente de 150 micra, e esterco bovino curtido de relação $\mathrm{C} / \mathrm{N}$ de 18:1 e cinza oriunda de fornalha de padaria, na proporção de 6:2:2, respectivamente (CHAGAS et al., 2006; PIRES et al., 2008).

A semeadura foi realizada utilizando quatro sementes por saco, sendo realizando desbaste após término da germinação, deixando-se apenas a plântula mais vigorosa por recipiente. As mudas quando atingiram $30 \mathrm{~cm}$ de altura, seis pares de folhas e na ocasião da emissão das primeiras gavinhas, foram padronizadas e instaladas em sistema de espaldeira a 2,2 $\mathrm{m}$ de altura do solo, utilizando espaçamento de $3 \times 3 \mathrm{~m}$.

As mudas em campo foram transplantadas em recipientes de polietileno utilizados como lisímetros de drenagem, com altura e diâmetro de 50 e $60 \mathrm{~cm}$, respectivamente, com capacidade para $141 \mathrm{dm}^{3}$ de substrato e possuindo drenos na parte final inferior, para se registrar o início da drenagem. O substrato utilizado no preenchimento dos lisímetros foi preparado a partir da mistura de um solo de textura arenosa $(84 \%$ areia, $8 \%$ silte e $8 \%$ argila) e esterco bovino curtido, nas proporções de 9:1. As características químicas do substrato são apresentadas nas Tabelas 1.

A preparação das águas salinas (CEai), foi realizada semanalmente pela diluição de uma água não salina $\left(\mathrm{C}_{1} \mathrm{~S}_{1}\right)$ com uma água de salinidade elevada $\left(\mathrm{C}_{4} \mathrm{~S}_{1}\right)$, Tabela 2 , armazenadas em caixas de fibra de vidro com capacidade para $5 \mathrm{~m}^{3}$.

As plantas foram irrigadas a cada dois dias com cada tipo de água, a partir do sétimo dia após o transplantio, utilizando sistema de irrigação localizada por gotejamento, instalado em cada lisímetro dois gotejadores tipo Catife, com vazão de $3,75 \mathrm{~L} \mathrm{~h}^{-1}$, cada um espaçado a $20 \mathrm{~cm}$ do caule da planta, fornecendo-se uma lâmina suficiente para elevar a umidade do solo ao nível de capacidade de campo. Para isso, a irrigação de cada parcela era cessada quando ocorria o início da drenagem, pelos drenos instalados na base final de cada lisímetro, das unidades experimentais.

O preparo do biofertilizante bovino foi realizado por fermentação anaeróbica, adicionando-se parte iguais de esterco fresco bovino e água não salina $\left(\mathrm{CEa} \leq 0,5 \mathrm{dS} \mathrm{m}^{-1}\right)$ em recipiente hermeticamente fechado durante, pelo menos, por trinta dias (SILVA et al., 2007).

O biofertilizante após fermentação, foi diluído em água na proporção de 1:1 (biofertilizante e água 
com $\mathrm{CE} \leq 0,5 \mathrm{dS} \mathrm{m} \mathrm{m}^{-1}$ ), aplicando-se no período correspondente, sobre a superfície do substrato contido nos lisímetros quantidade correspondente a $10 \%$ do volume do lisímetro. Após diluição e imediatamente antes da aplicação, foi coletado amostra do biofertilizante para análise salina como água para irrigação (Tabela 3), conforme EMBRAPA (2009).

Periodicamente, a cada 30 dias a após o transplantio, foi realizado adubações minerais de cobertura com nitrogênio $(\mathrm{N})$ e potássio $(\mathrm{K})$, mantendo a relação $\mathrm{N} / \mathrm{K}$ de $1: 1$, fertilizando os lisímetros com: $5 \mathrm{~g}$ de $\mathrm{N}$ e K planta ${ }^{-1}$ aos 30 dias, 10 g de $\mathrm{N}$ e K planta ${ }^{-1}$ aos 60 dias, 15 g de N e K planta $^{-1}$ aos 90 dias e aos 120 dias, 20 g de N e K planta $^{-1}$ (BORGES; CALDAS; LIMA, 2006). Em função dos elevados teores de fósforo e potássio no substrato (Tabela 1) não foi feita adubação de plantio.

Tabela 1. Características químicas do substrato (solo + esterco bovino) quanto à fertilidade.

\begin{tabular}{|c|c|c|c|c|c|c|c|c|c|c|}
\hline $\mathrm{pH}$ & $\mathrm{P}$ & $\mathrm{K}^{+}$ & $\mathrm{Ca}^{2+}$ & $\mathrm{Mg}^{2+}$ & $\mathrm{Na}^{+}$ & $\mathrm{H}^{+}+\mathrm{Al}^{3+}$ & $\mathrm{Al}^{3+}$ & SB & CTC & $\mathrm{MO}$ \\
\hline $1,0: 2,5$ & ---- $\mathrm{mg} \mathrm{dm}^{-3}$ & --- & --- & ------ & 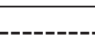 & $\mathrm{nol}_{\mathrm{c}} \mathrm{dm}^{-3}$ & $-----\cdot$ & 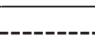 & --- & $\mathrm{g} \mathrm{dm}^{-}$ \\
\hline 7,36 & 216 & 666 & 3,37 & 0,90 & 2,02 & 2,25 & 0,00 & 7,99 & 10,24 & 14,84 \\
\hline
\end{tabular}

SB - soma de bases; CTC - capacidade de troca catiônica; $\mathrm{MO}$ - matéria orgânica

Fonte: Elaboração dos autores.

Tabela 2. Análise química das águas (A) utilizadas para irrigação salina (CEai).

\begin{tabular}{|c|c|c|c|c|c|c|c|c|c|c|c|}
\hline & $\mathrm{pH}$ & CEai & RAS & $\mathrm{Ca}^{2+}$ & $\mathrm{Mg}^{2+}$ & $\mathrm{K}^{+}$ & $\mathrm{Na}^{+}$ & $\mathrm{SO}_{4}^{2-}$ & $\mathrm{CO}_{3}^{2-}$ & $\mathrm{HCO}_{3}^{-}$ & $\mathrm{Cl}^{-}$ \\
\hline & \multicolumn{2}{|c|}{$\mathrm{dS} \mathrm{m}^{-1}$} & $\mathrm{mmol} \mathrm{L}^{-1}$ & & \multicolumn{7}{|c|}{ - } \\
\hline A1 & 6,40 & 0,50 & 2,12 & 1,67 & 0,81 & 0,11 & 2,37 & 0,86 & ALD & 1,12 & 3,14 \\
\hline A2 & 6,89 & 1,50 & 4,15 & 1,75 & 3,72 & 0,17 & 6,85 & 0,70 & ALD & 1,67 & 13,84 \\
\hline A3 & 7,27 & 2,50 & 5,87 & 2,06 & 5,26 & 0,29 & 11,20 & 0,48 & 0,05 & 2,41 & 29,01 \\
\hline A4 & 7,50 & 3,50 & 8,96 & 2,24 & 9,51 & 0,36 & 21,85 & 0,31 & 0,09 & 3,03 & 34,15 \\
\hline A5 & 7,81 & 4,50 & 11,05 & 2,82 & 14,94 & 0,47 & 32,82 & 0,29 & 0,11 & 3,28 & 41,05 \\
\hline
\end{tabular}

CEai $=$ Condutividade elétrica a $25^{\circ} \mathrm{C} ; \mathrm{RAS}=$ Razão de adsorção de sódio $\left[\mathrm{Na}^{+} /\left(\mathrm{Ca}^{2+}+\mathrm{Mg}^{2+} / 2\right)^{1 / 2}\right]$; $\mathrm{ADL}=\mathrm{Aquém}$ do limite de detecção.

Fonte: Elaboração dos autores.

As variáveis de crescimento, altura das plantas e o diâmetro caulinar, foram analisadas a partir do $15^{0}$ dia após o transplantio, sendo a altura das plantas do maracujazeiro amarelo medida semanalmente com trena milimetrada até as plantas atingirem a espaldeira, e os valores do diâmetro caulinar obtidos com paquímetro digital modelo Digimess ${ }^{\circledR}$ medido mensalmente a $10 \mathrm{~cm}$ do substrato até o 157 dias após o transplantio. Foram registrados também, os períodos do plantio à poda da haste principal e os períodos da poda dos ramos laterais.
Após mensuração e compilação do banco de dados com as variáveis, altura de plantas e diâmetro caulinar, calculou-se as taxas de crescimento absoluto e relativo, adotando a metodologia e as equações apresentadas por Benincasa (2003):

1. Taxa absoluta do crescimento em altura $(\mathrm{cm}$ $\left.\mathrm{dia}^{-1}\right):$ TCAA $=(\mathrm{hf}-\mathrm{hi}) *(\Delta \mathrm{t} 1)^{-1}$

2. Taxa relativa do crescimento em altura $(\mathrm{cm}$ $\left.\mathrm{cm}^{-1} \mathrm{dia}^{-1}\right): \mathrm{TCRA}=(\mathrm{Ln} \mathrm{hf}-\mathrm{Ln} \mathrm{hi}) *(\Delta \mathrm{t} 1)^{-1}$

3. Taxa absoluta do crescimento em diâmetro $\left(\mathrm{mm} \mathrm{dia}^{-1}\right): \mathrm{TCAD}=(\Theta \mathrm{f}-\Theta \mathrm{i}) *(\Delta \mathrm{t} 2)^{-1}$ 
4. Taxa relativa do crescimento em diâmetro $\left(\mathrm{mm} \mathrm{mm} \mathrm{mia}^{-1}\right): \mathrm{TCRD}=(\operatorname{Ln}$ Өf $-\mathrm{Ln} \Theta \mathrm{i}) *(\Delta \mathrm{t} 2)^{-1}$

sendo: hf = altura final da planta após a poda do meristema apical $(\mathrm{cm}) ;$ hi $=$ altura da planta aos 21 DAT $(\mathrm{cm}) ; \mathrm{Ln}=$ logaritmo neperiano (natural); $\Theta \mathrm{f}=$ diâmetro caulinar da planta ao final do experimento (mm); Өi = diâmetro caulinar da planta aos 21 DAT $(\mathrm{mm}) ; \Delta \mathrm{t} 1=$ tempo decorrido entre as leituras de $\mathrm{hf}$ e hi; $\Delta \mathrm{t} 2=$ tempo decorrido entre as leituras de $\Theta f$ e $\Theta i$.

Procedeu-se também a contagem dos números de ramos produtivos emitidos, contados a cada 10 dias a partir do 113 dias após transplantio das mudas nos lisímetros. O comprimento dos ramos produtivos, dos entrenós e o número de nós foram obtidos aos 60 e 150 dias após a poda da haste principal.

Os resultados foram submetidos à análise de variância e teste $\mathrm{F}$, a nível de $5 \%$ de significância. As médias foram submetidas à comparação pelo teste de Tukey para diagnóstico de efeitos qualitativos dos tratamentos, frequências de aplicação do biofertilizante e os valores quantitativos referentes aos níveis salinos das águas por regressão polinomial (BANZATTO; KRONKA, 2006), utilizando o programa SAS versão 9.2 (SAS, 2010).

\section{Resultados e Discussão}

O crescimento em altura das plantas de maracujazeiro amarelo não foi influenciado pela aplicação das águas salinas e pelas frequências de aplicação do biofertilizante, no entanto verificou-se efeito significativo entre as águas salina e o tempo de avaliação.

O aumento da salinidade da água de irrigação, ao longo do tempo, inibiu linearmente o crescimento em altura das plantas de maracujazeiro (Figura 1). As águas salinas com condutividade elétrica entre 0,5 e $2,5 \mathrm{dS} \mathrm{m}^{-1}$, não comprometeram o crescimento em altura das plantas, no entanto, com a elevação da concentração de sais da água de irrigação para as CEai de 3,5 e 4,5 dS m m. $^{-1}$ houve redução, evidenciando perda de $6,36 \%$ do crescimento em altura em relação aos tratamentos com menores CEai, apresentando média de $122,92 \mathrm{~cm}$.

Figura 1. Altura de plantas de maracujazeiro amarelo em função da CEai e a idade das plantas.

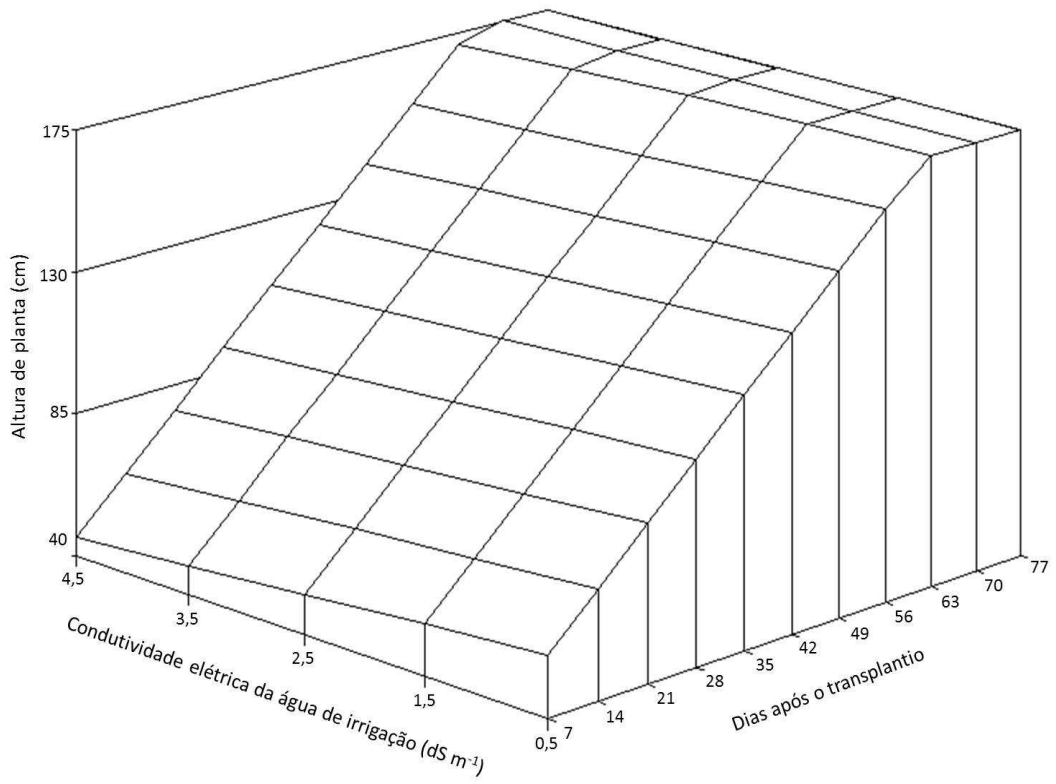

Altura $=46,11-3,56 \mathrm{C}+14,65 \mathrm{~T}+0,22 \mathrm{CT} * *$

$\mathrm{C}=$ Condutividade elétrica da água de irrigação; $\mathrm{T}=$ Dias após o transplantio

Fonte: Elaboração dos autores. 
Observa-se que aos 63 dias após o transplantio (Figura 1), as plantas de maracujazeiro tratadas com águas de CEai de 3,5 e 4,5 dS m $\mathrm{d}^{-1}$ ainda não tinham atingido a altura da espaldeira, havendo a necessidade de prolongar o período de avaliação das plantas em altura, por mais 14 dias, até que todas as plantas tivessem atingido $175 \mathrm{~cm}$, influenciando diretamente o período de podas da haste principal.

Resultados semelhantes foram obtidos por Soares et al. (2002), Cruz et al. (2006) e Cavalcante et al. (2009a) ao constatarem que o aumento da salinidade da água de irrigação promoveu declínio no crescimento, alocação e distribuição de macronutrientes em plantas jovens de maracujazeiro amarelo, durante o estabelecimento da cultura em campo.

Ayers e Westcot (1999) relata que a ação inibitória da salinidade das águas de irrigação no retardamento do crescimento das plantas do maracujazeiro amarelo, ocorre possivelmente devido a maior acumulação de sais no solo, principalmente quando irrigado com água de conteúdo salino superior a 2,0 $\mathrm{dS} \mathrm{m}^{-1}$, que provocam a diminuição do potencial osmótico do solo passando a atuar de forma negativa sobre o processo fisiológico, reduzindo a absorção de água pelas raízes, inibindo a atividade meristemática e o alongamento celular e, como consequência, causando redução no crescimento e desenvolvimento das mudas de maracujazeiro amarelo (CAVALCANTE et al., 2009b).

A aplicação dos tratamentos não exerceu efeitos significativos sobre a TCAA e a TCRA nas plantas de maracujazeiro amarelo obtendo, respectivamente, média de $1,97 \mathrm{~cm} \mathrm{dia}^{-1}$ e $0,0277 \mathrm{~cm} \mathrm{~cm}^{-1}$ dia $^{-}$ 1. Esses resultados demostram que o pomar de maracujazeiro amarelo apresentava fluxo constante de crescimento, durante o desenvolvimento e estabelecimento da cultura no campo, o que pode ter sido influenciado pelo curto período de aplicação dos tratamentos, insuficientes para resultarem em modificações biométricas do maracujazeiro.
Para o diâmetro do caule, registrou-se interação apenas para as idades das plantas de maracujazeiro amarelo (Figura 2), sendo negativamente afetado pelo incremento da salinidade da água a partir do 59 dias após transplantio. Verifica-se que apenas as águas com CEai superior a 2,5 $\mathrm{dS} \mathrm{m}^{-1}$, exerceram efeitos depressivos sobre o diâmetro do caule das plantas de maracujazeiro amarelo, e que os tratamentos irrigados com água de maior salinidade $\left(4,5 \mathrm{dS} \mathrm{m}^{-1}\right)$, as plantas apresentaram declínio de $10,93 \%$ no diâmetro do caule em relação às submetidas à água de $0,5 \mathrm{dS} \mathrm{m}^{-1}$, aos 157 dias após o transplantio (Figura 2).

Comparativamente, o comportamento observado na Figura 2, está em acordo com o apresentado por Cavalcante et al. (2007) que também verificaram decréscimos no diâmetro do caule em função do incremento de sais na água de irrigação, sendo que o contato das raízes com o meio adversamente salino contribui para maior e mais rápida absorção de sais que provocam depressividade a todos os órgãos das plantas, inclusive ao caule (NEVES et al., 2008; PRISCO; GOMES FILHO, 2010).

A inibição no crescimento com águas de CEai de 3,5 e 4,5 $\mathrm{dS} \mathrm{m}^{-1}$ foi provocada provavelmente pelo maior incremento de sais no substrato, que pode ter elevando a condutividade elétrica do extrato de saturação (CEes), resultando na diminuição dos efeitos osmóticos e iônicos, reduzindo a expansão e a divisão celular (MUNNS; JAMES; LAUCHLI, 2006; MUNNS; TESTER, 2008) nas plantas de maracujazeiro.

As condutividades elétricas das águas de irrigação promoveram redução da TCAD nas plantas de maracujazeiro amarelo até os 157 dias após o transplantio, indicando que independente do tempo, a adição de sais ao substrato, prejudicou o estabelecimento das mudas em campo, comprometendo o crescimento caulinar das plantas (Figura 3A). 
Figura 2. Diâmetro das plantas de maracujazeiro amarelo em função da CEai e a idade das plantas.

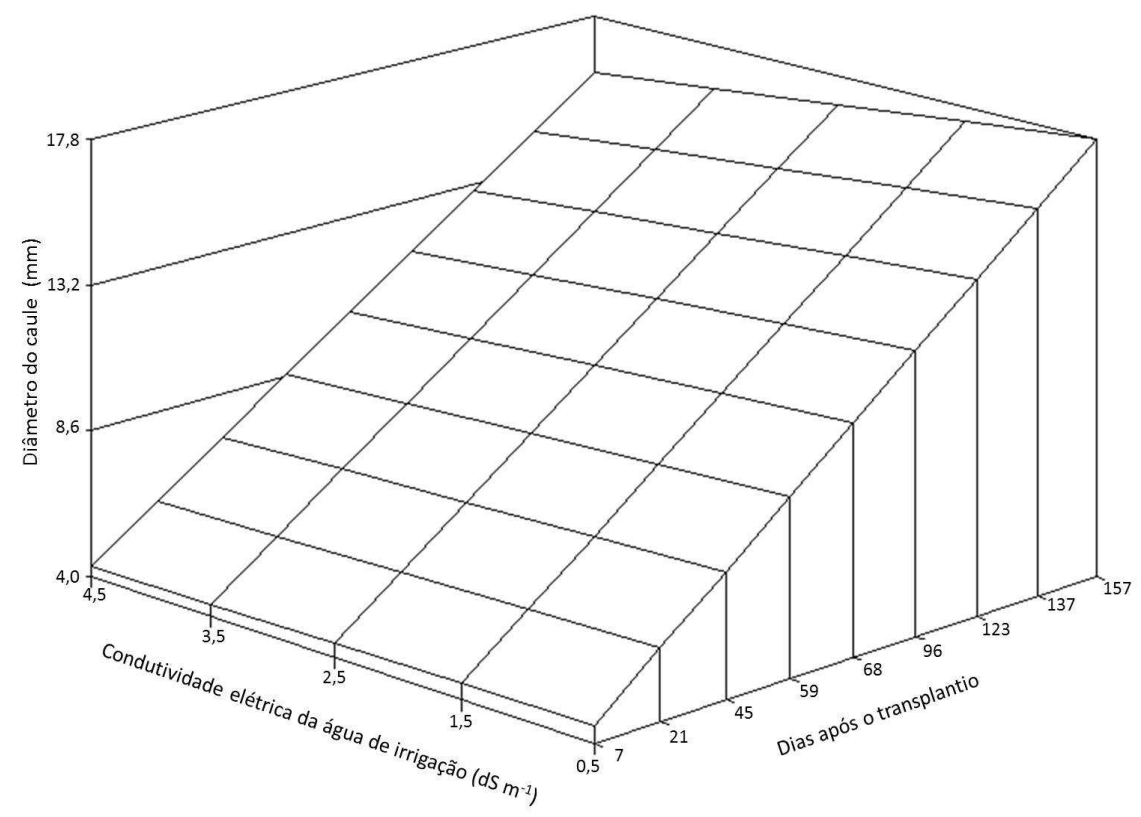

Altura $=2,89-0,0065 \mathrm{C}+1,67 \mathrm{~T}-0,052 \mathrm{CT} * *$

$\mathrm{C}=$ Condutividade elétrica da água de irrigação; $\mathrm{T}=$ Dias após o transplantio

Fonte: Elaboração dos autores.

Figura 3. Taxa de crescimento absoluta do diâmetro do caule (TCAD) de plantas do maracujazeiro amarelo em função das condutividades elétricas da água de irrigação (A) e das frequências de aplicação do biofertilizante (B). SB - sem biofertilizante; 1SAT - aplicação do biofertilizante 1 semana antes do transplantio, 90DAT - a cada 90 dias após transplantio, 1SAT+90DAT - 1 semana antes e a cada 90 dias, após transplantio.
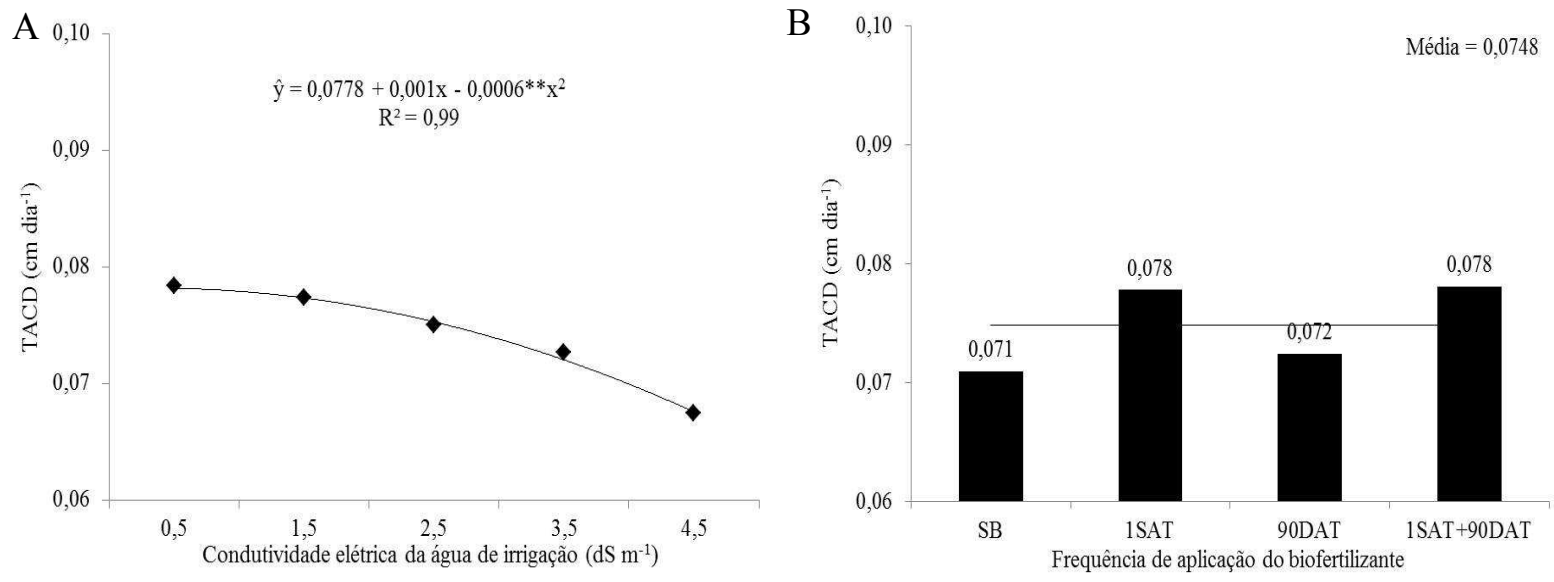

Fonte: Elaboração dos autores. 
A TCAD reduziu nas CEai superiores a 1,5 dS $\mathrm{m}^{-1}$, obtendo redução de até $13,95 \%$ nos tratamentos irrigados com água de condutividade elétrica de 4,5 $\mathrm{dS} \mathrm{m}^{-1}$, confirmando que a cultura do maracujazeiro amarelo é sensível aos efeitos salinos da água e do solo (AYERS; WESTCOT, 1999). Esses autores afirmam que à medida que a salinidade do solo aumenta em função da adição de sais proveniente da água de irrigação, a disponibilidade de água para a cultura diminui, havendo a necessidade de maior gasto metabólico de energia na tentativa de maximizar a absorção de água do solo, inibindo o crescimento vegetativo das culturas (MUNNS; TESTER, 2008). Segundo Richards (1954) a alocação e acumulação de sais solúveis nos tecidos das culturas, dependendo da fenofase da cultura e da quantidade, afetam consideravelmente o crescimento das plantas.
A interação frequência de aplicação do biofertilizante e TCAD (Figura 3B) não resultaram em diferença para o teste de médias, porém nas circunstâncias testadas a aplicação do biofertilizante uma semana antes do transplantio representadas pelos tratamentos 1SAT e 1SAT+90DAT, foram em média, os que mais estimularam o crescimento caulinar das plantas de maracujazeiro amarelo, obtendo 0,0779 $\mathrm{cm} \mathrm{cm}^{-1}$. Cavalcante et al. (2009b) afirmam que o biofertilizante fornecido uma semana antes da semeadura, promove maior crescimento das mudas de maracujazeiro amarelo, em relação à aplicação aos 30 dias após a emergência das plântulas.

O crescimento em diâmetro caulinar do maracujazeiro amarelo mensurado pela TCRD, não foi influenciado pelos tratamentos aplicados, observando redução dessa variável com a idade das plantas (Figura 4).

Figura 4. Taxa de crescimento relativo do diâmetro do caule (TRCD) das plantas do maracujazeiro amarelo em função dos dias após o transplantio.

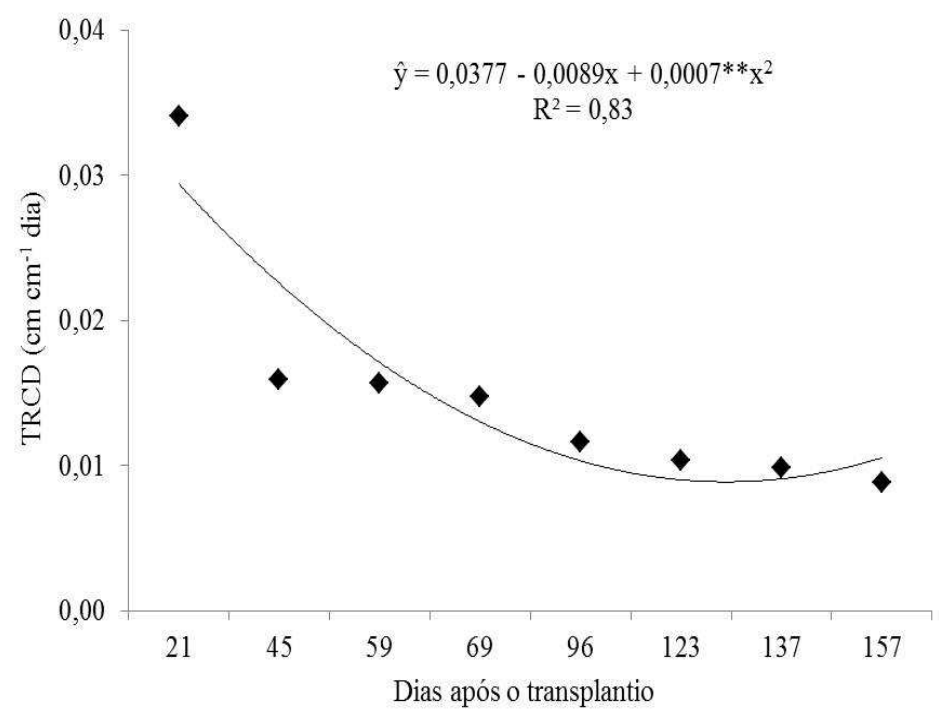

Fonte: Elaboração dos autores.

As plantas de maracujazeiro apresentaram crescimento máximo de diâmetro caulinar até os 21 dias após o transplantio com $0,034 \mathrm{~cm} \mathrm{~cm}^{-1} \mathrm{dia}^{-1}$ (Figura 4). Observa-se que apesar da redução dos valores, a partir dos 45 DAT houve tendência de estabilização dos valores da TCRD, que obtive o menor valor aos 157 DAT, com média de 0,0096 $\mathrm{cm} \mathrm{cm} \mathrm{clia}^{-1}$, ou seja, $71,76 \%$ inferior ao primeiro período de avaliação (21DAT). 
O comportamento da TRCD revela que o maracujazeiro amarelo obteve maior crescimento vegetativo durante a juvenilidade das plantas, sendo marcante a redução deste crescimento, no período mais próximo da maturação e do início da fase reprodutiva, onde os fotoassimilados são direcionados para a produção de flores e frutos, concordando com Larcher (2000) e Munns e Tester (2008), que citam haver mudanças de prioridade em função da fenofase das culturas, dentre elas, o maracujazeiro amarelo.

O número de dias para poda da haste principal do maracujazeiro amarelo sofreu efeito significativo da salinidade da água de irrigação e das frequências de aplicação do biofertilizante (Figura 5). Os resultados apresentados evidenciam uma redução no tempo entre a fase de transplantio e poda da haste principal, sob baixa salinidade da água
(Figura 5A). O incremento do teor salino da água prolongou o período da poda da haste principal, passando respectivamente de 47 para 53 dias após o transplantio entre as CEai de 0,5 e 4,5 dS m${ }^{-1}$ (Figura 5A). Os tratamentos com água de irrigação de condutividade igual a 1,$5 ; 2,5$ e $3,5 \mathrm{dS} \mathrm{m}^{-1}$, também elevaram o número de dias para poda, obtendo respectivamente 48, 50 e 51 dias após o transplantio do maracujazeiro amarelo.

O comportamento verificado na Figura 5 é resultante do fato que, as plantas irrigadas com água de maior condutividade elétrica foram comprometidas no crescimento em altura (Figura 1) pela adição de sais ao substrato, necessitando de um maior período de tempo para que a haste principal do maracujazeiro amarelo ultrapasse em $10 \mathrm{~cm}$ a espaldeira, para se proceder à eliminação da dominância apical.

Figura 5. Período do transplantio à poda da haste principal em plantas de maracujazeiro amarelo em função das condutividades elétricas da água de irrigação (A) e das frequências de aplicação do biofertilizante (B). SB - sem biofertilizante; 1SAT - aplicação do biofertilizante 1 semana antes do transplantio, 90DAT - a cada 90 dias após transplantio, 1SAT+90DAT - 1 semana antes e a cada 90 dias, após transplantio.

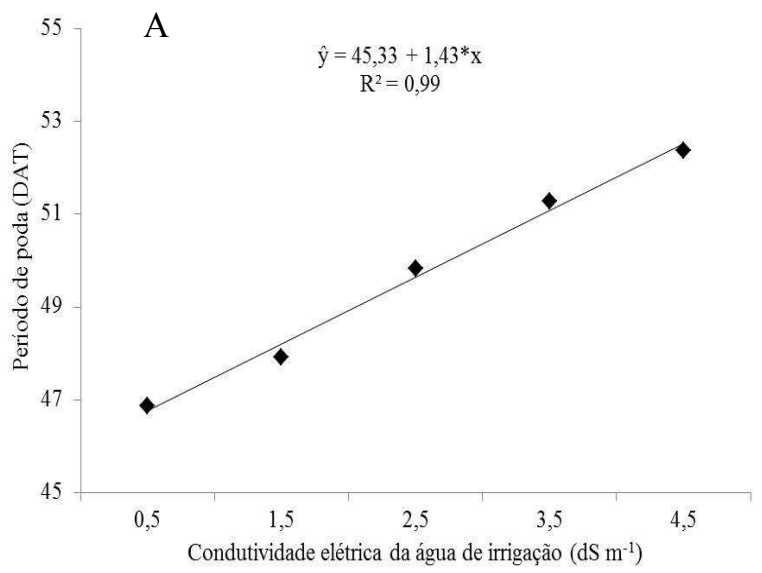

Fonte: Elaboração dos autores.

A adição do biofertilizante (Figura 5) antes do transplantio por estimular o crescimento em altura, pode ter exercido ação de ativador, fomentando o crescimento nas plantas de maracujazeiro, propiciando antecipação da poda da gema apical

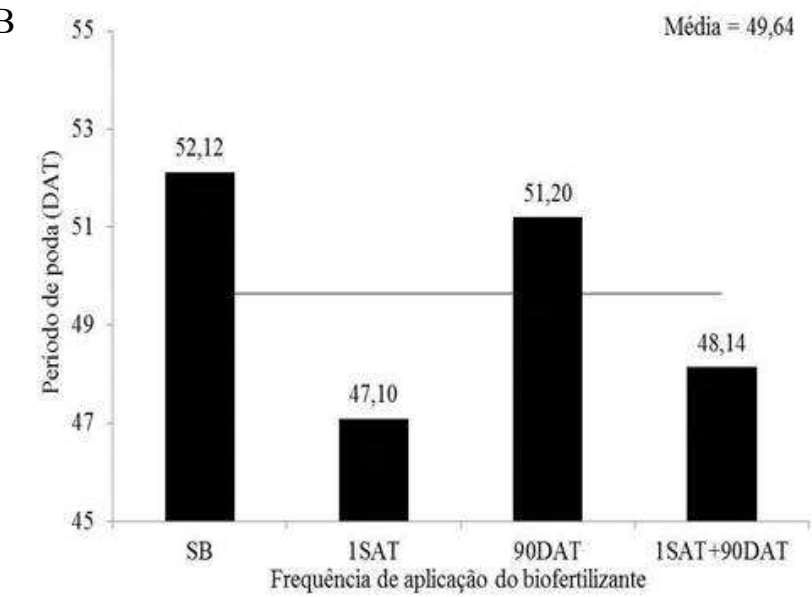

nos tratamentos 1SAT e 1SAT+90DAT (47 e 48 dias, respectivamente) em até uma semana, comparativamente em relação às plantas que não receberam o composto orgânico, SB e 90DAT (52 e 51 dias, respectivamente). 
A avaliação do período de poda do maracujazeiro é um componente importante, pois fornecer indicativos se a cultura está sofrendo algum tipo de estresse capaz de interferir no crescimento vegetativo da cultura, e caso isso ocorre, podemse adotar medidas necessárias para diagnosticar o fator limitante, eliminando ou minimizando seus efeitos para que não haja comprometimento na formação dos ramos secundários e terciários, e por consequente da produção.

A irrigação com água salina e as frequência de aplicação do biofertilizante não influenciaram os valores de números de ramos produtivos, que obtiveram médias de 17,91 ramos planta $^{-1}$ aos 153DAT, averiguando diferenciação apenas em relação aos períodos de avaliações (Figura 6).

Figura 6. Número de ramos produtivos por planta de maracujazeiro amarelo em função dos dias após o transplantio.

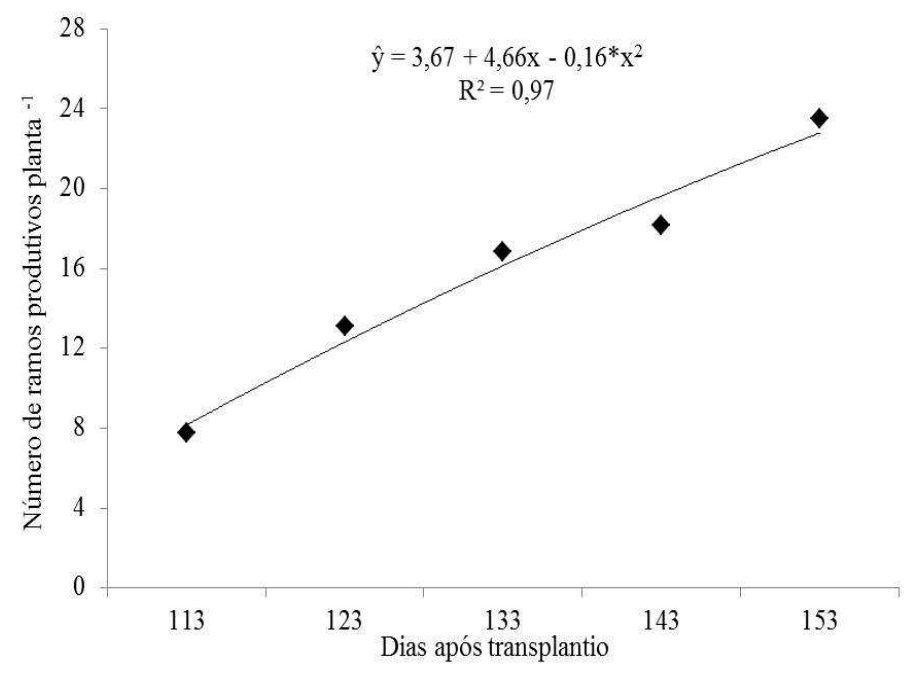

Fonte: Elaboração dos autores.

As avaliações de contagem dos ramos produtivos que foram iniciadas aos 90 dias após o transplantio, foram semelhantes, havendo diferença apenas nos valores obtidos a partir dos 113DAT, estimulado provavelmente pela poda dos ramos laterais, que foram realizadas em média aos 103DAT, passando aproximadamente de 8 para 24 ramos dos 113 aos 153DAT, respectivamente (Figura 6).

Os valores de número de ramos produtivos por planta são inferiores aos 34 ramos obtidos por Cavalcante et al. (2007) e semelhantes aos 24,7 ramos verificados por Rodolfo Júnior, Cavalcante e Buriti (2009) em plantas de maracujazeiro amarelo. Segundo Hafle et al. (2009), plantas de maracujazeiro com redução no número de ramos produtivos tendem a apresentar decréscimo na produção, pois resulta na diminuição do número de gemas floríferas e, consequentemente, a floração e a produção por planta.

Aos 160 DAT, o que corresponde a sete dias após término da desbrota dos ramos secundários, realizou-se avaliação dos espaçamentos entre os nós ou entrenós dos ramos secundários, verificando diferença estática em função dos tratamentos aplicados (Figura 7).

O suprimento com água salina reduziu a comprimento dos entrenós dos ramos secundários do maracujazeiro amarelo em aproximadamente $11,24 \%$, passando de 9,08 para 8,06 entrenós ramo- 
1 , respectivamente nas águas de 0,5 e $4,5 \mathrm{dS} \mathrm{m}^{-1}$ (Figura 7A). Observa-se que nas CEai de 0,5 e 1,5 $\mathrm{dS} \mathrm{m}^{-1}$, ocorre um menor comprometimento do crescimento dos entrenós do maracujazeiro irrigado com águas dessas condutividades. Já nas CEai de 2,5 e 3,5 dS m m $^{-1}$ ocorre redução de pelo menos 7,25\% no comprimento dos entrenós, sendo agravada pela condutividade de $4,5 \mathrm{dS} \mathrm{m}^{-1}$, que reduz em mais de $1 \mathrm{~cm}$ o comprimento dos entrenós nos ramos secundários.
As aplicações de biofertilizante, apesar da tendência de aumento do comprimento dos enternós, reportado pela maior frequência de aplicação do biofertilizante (1SAT+90DAT), não resultou em diferença para os valores avaliados (Figura 7B). Grattan e Grive (1999) e Cavalcante et al. (2010) afirmam que plantas conduzidas sobre condições de estresse salino são capazes de estimular e assimilar micronutrientes que influenciam na capacidade de antecipar ou retardar a fase de desenvolvimento e produção das plantas, comprometerem diretamente o número de botões florais, de flores abertas e de frutos.

Figura 7. Comprimento dos entrenós nos ramos produtivos por planta de maracujazeiro amarelo em função das condutividades elétricas da água de irrigação (A) e das frequências de aplicação do biofertilizante (B). SB - sem biofertilizante; 1SAT - aplicação do biofertilizante 1 semana antes do transplantio, 90DAT - a cada 90 dias após transplantio, 1SAT+90DAT - 1 semana antes e a cada 90 dias, após transplantio.

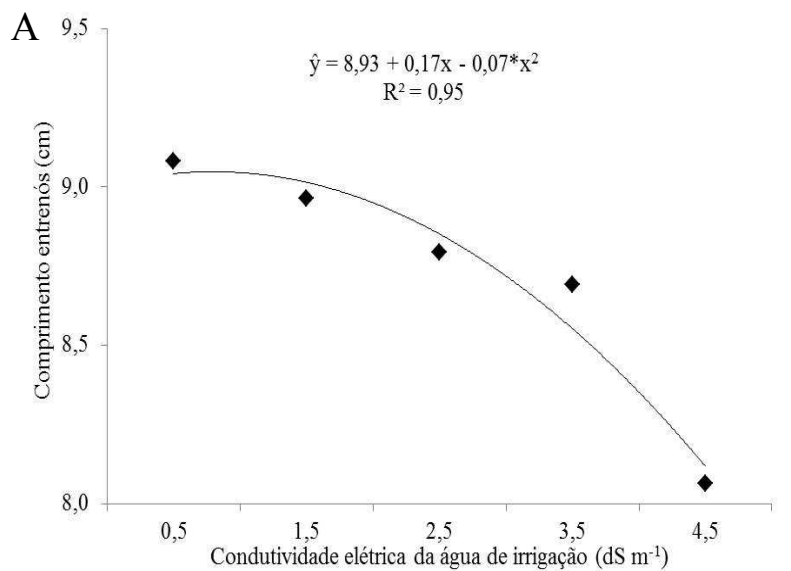

Fonte: Elaboração dos autores.

A salinidade da água de irrigação exerceu significativamente efeito prejudicial ao maracujazeiro, refletindo-se no declínio da emissão de botões florais (Figura 8). Plantas irrigadas com água de boa qualidade $\left(0,5 \mathrm{dS} \mathrm{m}^{-1}\right)$ apresentaram até 355 botões florais por planta reduzindo em 20,53 botões por incremento unitário da CEai, decrescendo em 27,32\% na CEai de 4,5 $\mathrm{dS} \mathrm{m}^{-1}$ que obteve 258 botões planta ${ }^{-1}$ (Figura 8). Provavelmente esse efeito prejudicial tenha sido causado pela acumulação de $\mathrm{Na}$, embora não tenham sido diagnosticados nas folhas sintomas visuais de toxidez. Esse

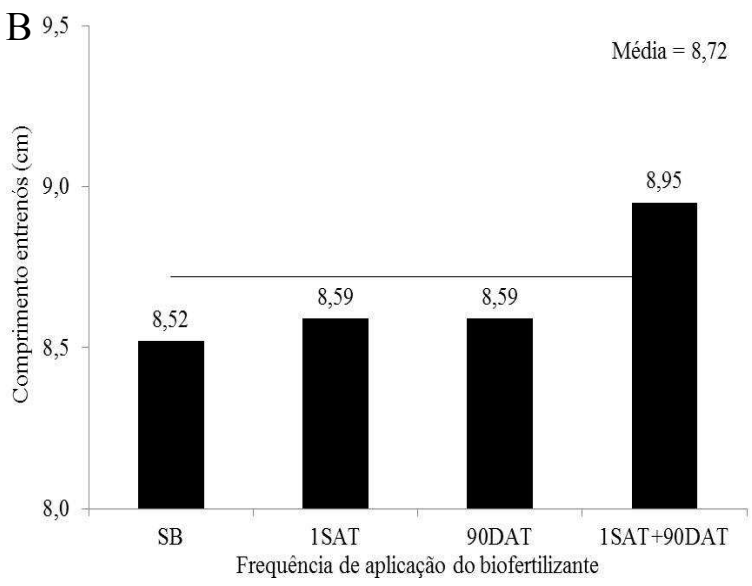

comportamento está coerente com Ayers e Westcot (1999) e Cavalcante et al. (2007) ao afirmarem que o maracujazeiro é uma cultura sensível aos efeitos salinos da água e do solo, principalmente na fase produtiva.

A redução do número de botões florais com o aumento da concentração de sais na solução do substrato pode ser decorrente da reação das plantas em condições de estresse hídrico, restringindo o potencial total da água, tornando-a menos disponível às plantas, reduzindo o alongamento celular e a população floral, na tentativa de garantir a 
preservação da espécie (CERQUEIRA et al., 2008). É provável ainda que, com a redução do fluxo de água entre o solo e a planta, tenha restringindo a captação de nutrientes pelo sistema radicular, dentre eles o nitrogênio, cuja função é estimular a formação e o desenvolvimento de gemas florais e proporcionar vegetação e perfilhamento das plantas (MALAVOLTA; VITTI; OLIVEIRA, 1997).

Essa suposição é reforçada pela ação mitigadora do biofertilizante, que elevou o número de botões florais por planta independente do período de aplicação do insumo orgânico e da condutividade elétrica da água de irrigação. Nota-se na Figura 8 , que o tratamento $1 \mathrm{SAT}+90 \mathrm{DAT}$ resultou no maior número de botões com média de 315 botões planta $^{-1}$, reduzindo em média para 294 botões nos tratamentos 90DAT e 1SAT, obtendo menor número no tratamento sem a adição do biofertilizante com média de 269 botões por planta ${ }^{-1}$.

Figura 8. Número de botões florais por planta de maracujazeiro amarelo em função das condutividades elétricas da água de irrigação e das frequências de aplicação do biofertilizante. SB - sem biofertilizante; 1SAT - aplicação do biofertilizante 1 semana antes do transplantio, 90DAT - a cada 90 dias após transplantio, 1SAT+90DAT - 1 semana antes e a cada 90 dias, após transplantio.

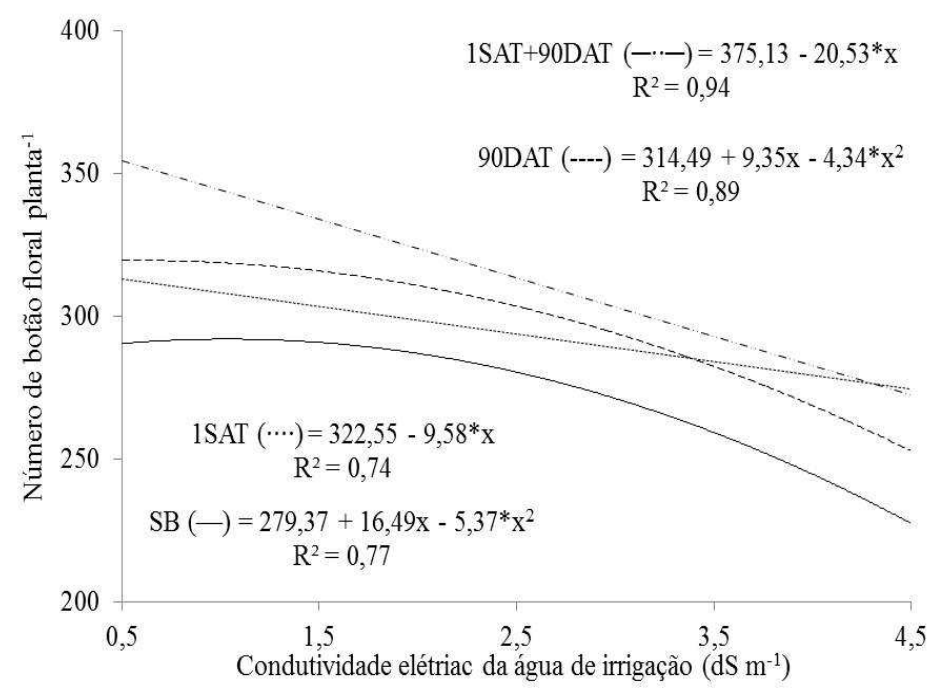

Fonte: Elaboração dos autores.

\section{Conclusões}

O aumento da salinidade da água de irrigação inibiu o crescimento em altura e o diâmetro caulinar das plantas de maracujazeiro amarelo, bem como retardou a poda da haste principal;

A irrigação com água de salinidade superior a 1,5 $\mathrm{dS} \mathrm{m} \mathrm{m}^{-1}$ provocou redução da distância dos entrenós e do número de botões florais dos ramos produtivos do maracujazeiro amarelo;

A aplicação do biofertilizante uma semana antes do transplantio proporcionou maior crescimento às plantas, bem como antecipação do período de poda da haste principal, em relação aos tratamentos sem os respectivos insumos.

O aumento da frequência de aplicação do biofertilizante atenuou os efeitos da salinidade da água de irrigação, elevando o número de botões florais por planta de maracujazeiro amarelo;

As plantas irrigadas com água de condutividade elétrica menor que $2,5 \mathrm{dS} \mathrm{m}^{-1}$ e com aplicação do biofertilizante realizada 1SAT+90DAT apresentaram maior crescimento vegetativo do maracujazeiro amarelo. 


\section{Agradecimentos}

Os autores expressam seus agradecimentos ao $\mathrm{CNPq}$ (Conselho Nacional de Desenvolvimento Científico e Tecnológico) pelo financiamento concedido para realização do trabalho (processos: 472864/2007-6 e 141513/2008-0).

\section{Referencias}

ALVES, G. S.; NASCIMENTO, J. A. M.; SANTOS, D.; ALVES, S. S. V.; SILVA, J. A. Fertilidade do solo cultivado com pimentão sob aplicação de diferentes tipos biofertilizantes. Revista Verde de Agroecologia e Desenvolvimento Sustentável, Mossoró, v. 4, n. 4, p. 33 41, 2009.

ARAÚJO, H. F.; COSTA, R. N. T.; CRISÓSTOMO, J. R.; SAUNDERS, L. C. U.; MOREIRA, O. C.; MACEDO, A.B.M. Produtividade e análise de indicadores técnicos do maracujazeiro-amarelo irrigado em diferentes horários. Revista Brasileira de Engenharia Agrícola e Ambiental, Campina Grande, v. 16, n. 2, p. 159-164, 2012.

AYERS, R. S.; WESTCOT, D. W. A qualidade de água na agricultura. 2. ed. Campina Grande: UFPB, 1999. 153 p. (FAO - Estudos Irrigação e Drenagem, 29).

BANZATTO, D. A.; KRONKA, S. N. Experimentação agricola. Jaboticabal: FUNEP, 2006. 247 p.

BENINCASA, M. M. P. Análise de crescimento de plantas. Jaboticabal: FUNEP, 2003. $41 \mathrm{p}$.

BEZERRA, A. K. P.; LACERDA, C. F.; HERNANDEZ, F. F. F.; SILVA, F. B. S.; GHEYI, H. R. Rotação cultural feijão caupi/milho utilizando-se águas de salinidades diferentes. Revista Ciência Rural, Santa Maria, v. 40, n. 5, p. 1075-1082, 2010.

BORGES, A. L.; CALDAS, R. C.; LIMA, A. A. Doses e fontes de nitrogênio em fertirrigação no cultivo do maracujá-amarelo. Revista Brasileira de Fruticultura, Jaboticabal, v. 28, n. 2, p. 301-304, 2006.

CAVALCANTE, L. F.; RODOLFO JÚNIOR, F.; SÁ; J. R.; CURVELO, C. R. S.; MESQUITA, E. F. Influência da água salina e matéria orgânica no desempenho do maracujazeiro amarelo e na salinidade do substrato. Irriga, Botucatu, v. 12, n. 4, p. 505-518, 2007.

CAVALCANTE, L. F.; SILVA, G. F.; GHEYI, H. R.; DIAS, T. J.; ALVES, J. C.; COSTA, A. P. M. Crescimento de mudas de maracujazeiro amarelo em solo salino com esterco bovino líquido fermentado. Revista Brasileira de Ciências Agrárias, Recife, v. 4, n. 4, p. 414-420, 2009a.
CAVALCANTE, L. F.; SOUSA, G. G.; GONDIM, S. C.; FIGUEIREDO, F. L.; CAVALCANTE, Í. H. L.; DINIZ, A. A. Crescimento inicial do maracujazeiro amarelo manejado em dois substratos irrigados com água salina. Irriga, Botucatu, v. 14, n. 4, p. 504-517, 2009b.

CAVALCANTE, L. F.; VIEIRA, M. S.; SANTOS, A. F.; OLIVEIRA, W. M.; NASCIMENTO, J. A. M. Água salina e esterco bovino líquido na formação de mudas de goiabeira cultivar Paluma. Revista Brasileira de Fruticultura, Jaboticabal, v. 32, n. 1, p. 251-261, 2010.

CAVICHIOLI, J. C.; CORRÊA, L. S.; BOLIANI, A. C.; SANTOS, P. C. Desenvolvimento e produtividade do maracujazeiro-amarelo enxertado em três porta-enxertos. Revista Brasileira de Fruticultura, Jaboticabal, v. 33, n. 2, p. 567-574, 2011.

CERQUEIRA, L. L.; FADIGAS, F. S.; PEREIRA, F. A.; GLOAGUEN, T. V.; COSTA, J. A. Desenvolvimento de Heliconia psittacorum e Gladiolus hortulanus irrigados com águas residuárias tratadas. Revista Brasileira de Engenharia Agrícola e Ambiental, Campina Grande, v. 12, n. 6, p. 606-613, 2008.

CHAGAS, I. M.; TAVARES, J. C.; FREITAS, R. S.; RODRIGUES, G. S. O. Formação de mudas de maracujá amarelo em quatro tamanhos de recipiente. Revista Verde de Agroecologia e Desenvolvimento Sustentável, Mossoró, v. 1, n. 2, p. 122-133, 2006.

COELHO, M. A.; SONCIN, N. B. Geografia do Brasil. São Paulo: Moderna, 1982. 368 p.

CRUZ, J. L. C.; PELACANI, C. R.; COELHO, E. F.; CALDAS, R. C.; ALMEIDA, A. Q.; QUEIROZ, J. R. Influência da salinidade sobre o crescimento, absorção e distribuição de sódio, cloro e macronutrientes em plântulas de maracujazeiro-amarelo. Bragantia, Campinas, v. 65, n. 2, p. 275-284, 2006.

DIAS, T. J.; CAVALCANTE, L. F.; FREIRE, J. L. O.; NASCIMENTO, J. A. M.; BECKMANNCAVALCANTE, M. Z.; SANTOS, G. P. Qualidade química de frutos do maracujazeiro-amarelo em solo com biofertilizante irrigado com águas salinas. Revista Brasileira de Engenharia Agrícola e Ambiental, Campina Grande. v. 15, n. 3, p. 229-236, 2011 a.

DIAS, T. J.; CAVALCANTE, L. F.; LEON, M. J.; SANTOS, G. P.; ALBUQUERQUE, R. P. F. Produção do maracujazeiro e resistência mecânica do solo com biofertilizante sob irrigação com águas salinas. Revista Ciência Agronômica, Fortaleza. v. 42, n. 3, p. 644-651, $2011 b$.

EMPRESA BRASILEIRA DE PESQUISA AGROPECUÁRIA - EMBRAPA. Manual de análises químicas de solos, plantas e fertilizantes. 2. ed. rev. atual. 
Brasília, DF: Embrapa Informação Tecnológica, 2009. $627 \mathrm{p}$.

GRATTAN, S. R.; GRIEVE, C. M. Mineral nutrient acquisition and response by plants grown in saline environments. In: PESSARAKLI, P. (Ed.). Handbook of plant and crop stress. 2. ed. New York: Marcel Dekker, 1999. p. 203-229.

HAFLE, O. M.; RAMOS, J. D.; LIMA, L. C. O.; FERREIRA, E. A.; MELO, P. C. Produtividade e qualidade de frutos do maracujazeiro-amarelo submetido à poda de ramos produtivos. Revista Brasileira de Fruticultura, Jaboticabal, v. 31, n. 3, p. 763-770, 2009.

LARCHER, W. Ecofisiologia vegetal: as influências do ambiente sobre o crescimento e sobre o desenvolvimento. Tradução Carlos Henrique B. A. Prado. São Carlos: Rima, 2000. 296 p.

MALAVOLTA, E.; VITTI, G. C.; OLIVEIRA, S. A. Avaliação do estado nutricional das plantas: princípios e aplicações. 2. ed. Piracicaba: POTAFOS, 1997. 319 p.

MESQUITA, E. F.; CAVALCANTE, L. F.; GONDIM, S. C.; CAVALCANTE, Í. H. L.; ARAÚJO, F. A. R.; BECKMANN-CAVALCANTE, M. Z. Produtividade e qualidade de frutos do mamoeiro em função de tipos e doses de biofertilizantes. Semina: Ciências Agrárias, Londrina, v. 28, n. 4, p. 589-596, 2007.

MUNNS, R.; JAMES, R. A.; LAUCHLI, A. Approaches to increasing the salt tolerance of wheat and other cereals. Journal of Experimental Botany, United Kingdom, v. 57, n. 5, p. 1025-1043, 2006.

MUNNS, R.; TESTER, M. Mechanisms of salinity tolerance. Annual Review of Plant Biology, Palo Alto, v. 59, n. 1, p. 631-681, 2008.

NEVES, A. L. R.; LACERDA, C. F.; GUIMARÃES, F. V. A.; GOMES FILHO, E.; FEITOSA, D. R. C. Trocas gasosas e teores de minerais no feijão-de-corda irrigado com água salina em diferentes estádios. Revista Brasileira de Engenharia Agrícola e Ambiental, Campina Grande, v. 13, p. 873-881, 2009. Suplemento.

OULD AHMED, B. A.; MORITANI, M. I. S. Effect of saline water irrigation and manure application on the available water content, soil salinity, and growth of wheat. Agricultural Water Management, Amsterdam, v. 97, n. 1, p. 165-170, 2010.
PIRES, A. A.; MONNERAT, P. H.; MARCIANO, C. R.; PINHO, L. G. R.; ZAMPIROLLI, P. D.; ROSA, R. C. C.; MUNIZ, R. A. Efeito da adubação alternativa do maracujazeiro amarelo nas características químicas e físicas do solo. Revista Brasileira de Ciências do Solo, Viçosa, v. 32, n. 5, p. 1997-2005, 2008.

PRISCO, J. T.; GOMES FILHO, E. Fisiologia e bioquímica do estresse salino em plantas. In: GHEYI, H. R.; DIAS, N. S.; LACERDA, C. F. (Ed.). Manejo da salinidade na agricultura: estudos básicos e aplicados. Fortaleza: INCTSal, 2010. p. 143-160.

RICHARDS, L. A. Diagnostico y recuperación de suelos salinos y sódicos. México, 1954. 172 p. (Manual de Agricultura, 60).

RODOLFO JÚNIOR, F.; CAVALCANTE, L. F.; BURITI, E. S. Crescimento e produção do maracujazeiro-amarelo em solo com biofertilizantes e adubação mineral com NPK. Revista Caatinga, Mossoró, v. 22, n. 2, p. 134-145, 2009.

SAS INSTITUTE. SAS 9.2 user's guide. 2. ed. USA: Cary, NC, 2010. 2188 p.

SILVA, A. F.; PINTO, J. M.; FRANÇA, C. R. R. S.; FERNANDES, S. C.; GOMES, T. C. A.; SILVA, M. S. L.; MATOS, A. N. B. Preparo e uso de biofertilizante líquido. Petrolina: EMBRAPA Semi-Árido, 2007. 4 p. (Comunicado técnico, 30).

SOARES, F. A. L.; GHEYI, H. R.; VIANA, S. B. A.; UYEDA, C. A.; FERNANDES, P. D. Water salinity and initial development of yellow passion fruit. Scientia Agricola, Piracicaba, v. 59, n. 3, p. 491-497, 2002.

SOUZA, G. B.; CAVALCANTE, L. F.; CAVALCANTE, I. H. L.; BECKMAN-CAVALCANTE, M. Z.; NASCIMENTO, J. A. M. Salinidade do substrato contendo biofertilizante para a formação de mudas de maracujazeiro irrigado com água salina. Revista Caatinga, Mossoró, v. 21, n. 2, p. 172-180, 2008.

SOUZA, G. G.; MARINHO, A. B.; ALBUQUERQUE, A. H. P.; VIANA, T. V. A.; AZEVEDO, B. M. Crescimento inicial do milho sob diferentes concentrações de biofertilizante bovino irrigado com águas salinas. Revista Ciência Agronômica, Fortaleza, v. 43, n. 2, p. 237-245, 2012.

TEJADA, M.; GONZALEZ, J. L.; GARCÍAMARTÍNEZ, A. M.; PARRADO, J. Effects of different green manures on soil biological properties and maize yield. Bioresource Technology, New York, v. 99, n. 6, p. 1758-1767, 2008. 